\title{
BELEZA E MODA DA MULHER REPRESENTADAS NA IMPRENSA FEMININA DOS SÉCULOS XX E INÍCIO DO XXI
}

\author{
Daiane Lopes da Silva ${ }^{1}$ \\ Mestre em Língua Portuguesa (PUC-SP) \\ Joani Almeida dos Santos Nogueira ${ }^{2}$ \\ Mestre em Língua Portuguesa (PUC-SP)
}

\section{RESUMO}

Neste artigo, investigamos revistas produzidas no século XX e início do XXI e a maneira como as mulheres são representadas. Nosso estudo está voltado para cinco publicações: Jornal das Moças (1914); Revista Feminina (1936); Querida (1968); Capricho (1999) e Vogue Brasil (2018). Para a presente análise, temos o entrelaçamento entre duas áreas científicas, História e Linguística, que resultaram na História das Ideias Linguísticas. Este estudo, ainda que fragmentado, pois fizemos um breve recorte de diferentes materiais, apresenta um novo olhar sobre a História, distinta daquela que valorizava apenas figuras heroicas, os grandes feitos e as realizações consideradas relevantes. Desse modo, constatamos o postulado de Chartier (1990, p.16-17), que defende a maneira "como, em diferentes lugares e momentos, uma determinada realidade social é construída e dada a ler".

Palavras-chave: Imprensa feminina. Representação. Beleza. Moda.

\section{Introdução}

É notória a importância da imprensa na constituição da sociedade, na qual figura como fonte de (in)formação e de persuasão. Utilizada como meio de comunicação, ela é capaz de ditar comportamentos e regras que, ao longo da história, se mostram presentes em distintos contextos. Por intermédio dos estudos da História e da Linguística, é possível verificar que a imprensa não apenas se constitui como suporte de informação, mas também fonte histórica e documental. Nesse sentido, nosso estudo é voltado para o universo feminino, por meio de publicações destinadas às mulheres, com o objetivo de entender de que modo elas são representadas, bem como a sua relação com a beleza, com o corpo e com a vida em sociedade.

Sob esse viés, verificamos a importância de discutir o comportamento da sociedade nos séculos XX e início do XXI, com foco na figura da mulher. Como fonte de entretenimento, as revistas femininas tornaram-se objeto de consumo, pois esses materiais apresentam assuntos

\footnotetext{
${ }^{1}$ lopespdaiane@gmail.com

2 joani.santosnogy@gmail.com
} 
relacionados à época de cada publicação; moda, beleza e comportamento sempre estiveram presentes no imaginário feminino. Neste artigo, investigamos revistas dos períodos já mencionados e a maneira como as mulheres são representadas. Nossa pesquisa está voltada para cinco publicações: Jornal das Moças (1914); Revista Feminina (1936); Querida (1968); Capricho (1999) e Vogue Brasil (2018).

O aporte teórico do qual nos valemos corresponde aos estudos sobre História das Ideias Linguísticas e História Cultural, desenvolvidos pelos seguintes autores: Chartier (1990); Fávero e Molina (2006); Pollini (2007); Buitoni (2009); Del Priore (2014); e Wolf (2021).

O presente artigo está organizado da seguinte maneira, além desta introdução e das considerações finais: Imprensa como fonte histórica; A imprensa na sociedade do século XX; Imprensa feminina; Beleza; Moda e a análise propriamente dita. Para tanto, seguimos a ordem cronológica das publicações, a fim de observar, nos textos, nas fotografias e nas ilustrações, como as cinco publicações se direcionavam às mulheres, em relação ao nosso foco de investigação.

\section{A imprensa como fonte histórica}

A análise desses materiais como documento histórico tornou-se aplicável a partir dos questionamentos feitos pelos historiadores da Escola dos Annales, pois, para eles, o fazer histórico deve diferenciar-se de "tecer cronologias de fatos com personagens importantes". (FÁVERO; MOLINA, 2006, p.18). A partir da divulgação das ideias de pesquisadores como Lucien Febvre e Marc Bloch, passou-se à construção de uma História distante dos padrões, isto é, daquilo que, por muito tempo, foi tradição; atualmente, é um campo interdisciplinar, que, por meio de diálogos com diferentes áreas do conhecimento, interpreta os fatos do passado.

Nosso interesse, no presente artigo, é a abordagem baseada nos estudos da terceira geração dos Annales representada por estudiosos como Le Goff, Le Roy e Chartier. Esses autores, conforme pontuam Fávero e Molina (2006, p. 21), foram fortemente influenciados pelo estruturalismo, com o uso da metáfora "do porão ao sótão", ou seja, repensaram a História, relacionando-a com fatos ligados aos aspectos culturais de determinadas sociedades.

Essa expressão é uma alusão ao novo fazer historiográfico; deixam-se em segundo plano os documentos tradicionais nos porões, e passa-se a estudar outras fontes cotidianas, que estão no sótão, por serem registros sem artifícios. Por essa razão, é possível encontrar fatos verídicos 
por intermédio de diferentes fontes, nas modalidades oral ou escrita, o que permite também elucidar a História por meio de estudos da cultura popular.

De acordo com Kreniski e Aguiar (2011, p. 3),

[...]as pesquisas realizadas na história abrem-se para novas possibilidades, tendo uma nova abordagem para os acontecimentos históricos, estamos tratando agora da história de gênero, da criança, do operário das mulheres, não mais a história econômica e política como centro de estudo para construção da história, é o partir do micro para o macro. E são estas modificações nos temas a serem abordados que remetem o historiador a novas fontes, a novos questionamentos e novas interpretações e reflexões por parte dos historiadores que agora não precisam mais esconder a suas opiniões a respeito dos temas trabalhados, ele não age mais de forma imparcial quando se debruça sobre a sua fonte $(2011$, p. 3$)$.

Por ser uma área em que a subjetividade é notória, pois a História está atrelada ao contexto social e ideológico, é possível representar fatos a partir de diferentes concepções. Por essa razão, ela pode ser estudada em conjunto com diferentes áreas do saber, como a linguística. A partir de estudos científicos desenvolvidos sobretudo por Sylvain Auroux, concebeu-se um novo domínio denominado História das Ideias Linguísticas. Dentre outros saberes, ela está intimamente ligada à perspectiva linguística, ou seja "como um sujeito - por meio da linguagem - interpreta, elabora e constrói/reconstrói uma dada realidade social” (MARTINO, 2021, p. 3). E é justamente nessa perspectiva que o presente estudo se enquadra.

Assim, a História das Ideias Linguísticas busca trazer à luz textos de diferentes áreas do conhecimento, com o intuito de detectar particularidades "linguísticas, enunciativas e discursivas que o auxiliem a esboçar um conjunto representativo de uma certa época, contextualizada histórica e ideologicamente" (SILVA, 2021, p. 20).

\section{A imprensa na sociedade brasileira do século $\mathrm{XX}$}

Foi no século XX que, de acordo com Lima (2007, p. 224) a sociedade brasileira sofreu diversas transformações, especialmente em dois estados do sudeste do Brasil, São Paulo e Rio de Janeiro, em virtude da expansão urbana e de melhorias em relação ao nível instrucional. Desse modo, a imprensa também se modernizou, com intuito de atender à demanda, já que, cada vez mais, as pessoas tinham acesso à informação e à leitura.

A autora também destaca que, em 1912, São Paulo estava no topo da lista como o estado que mais publicava periódicos em relação à média nacional. Segundo a pesquisadora, até 1929, houve um total de 66 publicações. Além disso, as revistas ganharam notoriedade, aumento de 
leitoras e, devido à modernização da imprensa, por meio de artes gráficas, esses materiais foram enriquecidos com fotografias e ilustrações.

A mulher modelo era descrita como aquela cujas qualidades são múltiplas: responsável pela casa, pelo lar e pelo marido. Ademais, ela teria de arranjar tempo para cuidar de si mesma. Essas atribuições são conhecidas até a atualidade, embora algumas já sejam consideradas obsoletas. Porém, a responsabilidade e a cobrança das quais as mulheres são alvo advêm do século XX, ou seja, muito antes da invenção de programas de edições fotográficas, dos filtros em redes sociais ou de intervenções cirúrgicas. Desde essa época, as revistas ditavam os padrões a ser seguidos.

Em estudo publicado em 2020, já havíamos constatado esse fato, ao examinarmos prefácios de livros culinários ${ }^{3}$. Na ocasião, verificamos que, ao longo de todo o século $\mathrm{XX}$, a mulher foi a responsável pelo lar, pelo marido e pelos filhos e ainda precisava ter vaidade, estar sempre apresentável.

Seguindo essa linha, buscamos analisar, em revistas femininas que circularam em dois séculos diferentes, a representação da mulher. Trata-se, portanto, de materiais constituídos de diferentes gêneros textuais e considerados de interesse do universo da mulher.

\section{Imprensa feminina}

De acordo com Antonio (2009), ao citar Buitoni (1986, p. 16), sobre a imprensa feminina, é correto afirmar que ela

[...]nasceu sob o signo da literatura, logo depois acompanhado pelo da moda. Nos primeiros tempos, moda e literatura dividiam as atenções. Os direitos femininos entraram em cena nos séculos XVIII e XIX, às vezes como dominantes. Paralelamente, os signos da utilidade iam-se introduzindo e ganhando espaço: trabalhos manuais, conselhos de saúde e economia doméstica.

O surgimento de suportes comunicativos voltados para a imprensa feminina, ainda segundo Antonio (2009, p. 34), deu-se sobretudo em razão da luta pelos direitos femininos, já que, naquele momento, se discutiam questões de igualdade entre homens e mulheres. Sullerot (1963) afirma que os periódicos femininos “se proclamam destinados à clientela feminina e que

\footnotetext{
${ }^{3}$ SILVA, Daiane Lopes da; NOGUEIRA, Joani Almeida dos Santos. Um olhar sobre a representação em livros de culinária dos séculos XX e XXI. In: MARTINO, Agnaldo (ORG.). Itinerários Investigativos: história das ideias linguísticas: apropriação e representação. São Paulo: Blucher, 2021. (p. 109-120).
} 
foram concebidos objetivando um público feminino". No que concerne à imprensa feminina, ela está voltada para a defesa de causas (BUITONI, 1986, apud ANTONIO, 2009, p. 34).

A imprensa destinada às mulheres surgiu na Europa, no final do século XVII, e "o primeiro periódico foi Lady's Mercury, lançado em 1693, na Inglaterra” (SOUZA, 2002, p.16). Entretanto, no Brasil, publicações dedicadas ao sexo feminino ocorreram no início do século XIX.

As revistas direcionadas às "madames" brasileiras passaram por um grande processo de transformação. Inicialmente, tratavam de moda, literatura, artes, cuidados com a família e a casa. No século XX, além de focalizarem tendências e comportamento, passaram a tratar de temas como beleza, trabalho e a luta pela igualdade de gênero.

Ademais, os exemplares femininos tiveram como característica integrar a mulher à sociedade de consumo. Nesse sentido, as revistas traziam, cada vez mais, anúncios para impulsionar o capitalismo:

[...]a lógica da moda se expandiu e não está mais exclusivamente para a indumentária, não está mais só ao que se refere às roupas, mas, sim, no consumo em geral e também ao universo que rodeia os seus principais interesses de informação. E é isso que faz as revistas femininas sobreviverem no mercado editorial: assuntos específicos e especializados na mulher, conteúdo novo e instigante todo o tempo, mostrando para a sua leitora em primeira-mão aquilo que ela vai ter vontade de consumir nos próximos dias (MENEGUETE, 2012, p. 12).

No século XXI, a imprensa feminina acompanha uma mulher emancipada, que deseja “construir, aprender, se divertir, mudar o planeta, vivenciar opções bem diferentes das previstas nos planos traçados sem sua participação" (SOUZA, 2002, p. 22). No entanto, é também uma mulher exposta aos estereótipos de beleza difundidos nos meios de comunicação, como em nenhuma outra época.

Nesse sentido, em busca desse padrão inatingível de beleza, as mulheres procuram por procedimentos estéticos, construídos por meios de técnicas e tecnologias: ginástica, musculação, modelagem por implantes, enxertos, cirurgias plásticas entre outros. Esse tipo de manipulação estética do corpo é uma preocupação para a maioria das consumidoras, atualmente. 


\section{Beleza}

A palavra beleza remete-nos àquilo que é bonito e apreciável. A sua origem vem do latim bellus $^{4}$ - "bonito, bem-apessoado, encantador". Ademais, a beleza está relacionada aos padrões impostos por uma sociedade, algo que pode variar de uma cultura para outra:

[...]registra seu antecedente no latim bellus, entendendo a ideia de bonito, e o sufixo -eza, para atribuir relação. Responde também à influência dos padrões sociais, do saber e da subjetividade individual, identificando mudanças de avaliação ao longo do tempo, portanto a manifestação da beleza tem que ser lida segundo a época ou momento, e as circunstâncias socioculturais específicas (VESCHI, 2019) .

Há muito tempo, o culto à aparência física é manifestado pela humanidade e, nesse sentido, o sexo feminino foi mais evidenciado. Conforme a hipótese de Wolf (2021, p. 32), "a forma pela qual as mulheres sempre pensaram na "beleza" remonta no máximo a 1830, quando se consolidou o culto à domesticidade e se inventou o código da beleza”. Isso se deu, pois:

[...]novas tecnologias tinham condições de reprodução - em figurinos, daguerreótipos, ferrotipias e rotogravuras - imagens de como deveria ser a aparências das mulheres. Na década de 1840, foram tiradas as primeiras fotografias de prostitutas nuas. Anúncios com imagens de "belas" mulheres apareceram pela primeira vez em meados do século. Reproduções de obras de arte clássicas, cartões-postais com beldades da sociedade e amantes de reis, gravuras da Currier and Ives e bibelôs de porcelana invadiram a esfera isoladas à qual estavam confinadas as mulheres da classe média (WOLF, 2021, p. 33).

Desse modo, as mulheres foram, ao longo do tempo, carregando a postura do belo ou buscando "essa tal beleza" para acompanhar os padrões culturais de cada momento histórico. Para Wolf (2021, p. 31) "as qualidades que um determinado período considera belas nas mulheres são apenas símbolos do comportamento feminino que aquele período julga ser desejável". Dessa maneira, os grandes aliados do ideal de formosura feminina levam em conta as vestimentas, cosméticos e mudanças no corpo para se adequar a uma determinada moda e, por conseguinte, alcançar um padrão estabelecido socialmente.

\footnotetext{
${ }^{4}$ Disponível em: https://origemdapalavra.com.br/palavras/beleza/ ._Acesso em: 10 de setembro de 2021

${ }^{5}$ Benjamin Veschi. Ano: 2019. Disponível Em: https://etimologia.com.br/beleza/._Acesso em: 10 de setembro de 2021
} 


\section{Moda}

O vocábulo moda originou-se do latim modus, o mesmo que "modo" e “comportamento". De acordo com Pollini, (2007), o termo surgiu:

[...]no século XV, a palavra Mode começou a ser utilizada em francês (significado basicamente "modo"), tendo se desenvolvido a partir da palavra latina Modus, que fazia referência à medida agrária, e mais tarde passou a significar também "maneira de se conduzir". [...] Este sentido de "ao modo", "à maneira", passou a designar os gostos, as preferências, como também a maneira como as pessoas se vestiam, suas escolhas estéticas, suas opiniões e gostos do momento. A moda está muito relacionada a um conjunto de fatores, a um sistema de funcionamento social, do que especificamente às roupas, que são apenas a ponta desse iceberg (p. 18, grifos da autora).

Designada ao costume/hábito de determinada sociedade, no decorrer dos tempos, ela passou a ser relacionada ao mercado e à oferta, tornando-se uma espécie de mecanismo que controla as preferências dos indivíduos. Dito de outro modo, faz referência a algo que está sempre mudando e é criado para agradar e atender ao maior número de consumidores; trata-se de um modelo de pressão social, que indica o que se deve consumir ou fazer.

Assim, é essencial entender como era a moda no século XX, a fim de compreendê-la no presente, pois ela é um produto de seu tempo; dialoga com o contexto em que se insere e se modifica, a partir do momento em que a cultura, a política, a economia e a sociedade sofrem transformações. Nesse sentido, o indivíduo se apropria das tendências do contexto histórico no qual se encontra, guiado não só por seus gostos ou pela realidade que o cerca. Ele também as utiliza como uma forma de expressão, ou seja, "as roupas, como artefatos, 'criam' comportamentos por sua capacidade de impor identidades sociais e permitir que as pessoas afirmem identidades sociais latentes" (CRANE, 2006, p. 22).

O século passado foi um período de grandes transformações: as extravagâncias, na famosa década de 1920; a escassez, devido às Guerras Mundiais; as Revoluções da Industrialização, nos chamados Anos Dourados. Além disso, caracterizou-se pelas grandes lutas por igualdade, em que a mulher busca seu espaço na sociedade. De maneira geral, o que ocorria nas grandes potências mundiais refletia socialmente. Isso não foi diferente no Brasil, que sofreu grandes influências da moda europeia e americana. Inicialmente, por meio dos grandes estilistas 
franceses; depois, pelo cinema hollywoodiano, rádio, TV, e também pela imprensa feminina, foco do presente artigo.

\section{Imprensa feminina em análise}

Para realizarmos nossa análise, com relação a beleza e moda das mulheres, ocupamonos de revistas femininas de diferentes décadas, seguindo uma ordem cronológica: Jornal das Moças (1914); Revista Feminina (1936); Querida (1968); Capricho (1999); Vogue Brasil (2018).

Segundo Buitoni (2009), a mulher do século passado tinha particularidades observadas ao longo das décadas:

[...] uma análise semântica bastante livre e ás vezes saudavelmente impressionista permitiu-lhe identificar, por exemplo, a "mulher oásis", no exemplo da belle époque; a "mãe sofredora", na imprensa contemporânea à Primeira Guerra Mundial; a "sacerdotisa da beleza", em anos de rápida modernização burguesa lastreada de condições ideológicas; "Iracema de lábios grossos", exemplo de crônica sobre a mulher do povo, típica dos anos 1930; a "mulher- celuloide", símbolo do processo de americanização, à Hollywood, durante a Segunda Guerra Mundial; a "garota moderna" lançada pela moda empresarial dos anos 1950; a "dona de casa insatisfeita", que já sofre a febre consumista (e as respectivas frustrações domésticas) dos anos de desenvolvimento; enfim, a " liberdade" e a "marginal", nossas contemporâneas, oriundas maciçamente para a fruição do sexo e da libido aquisitiva, ou para a participação nos grupos e no movimentos políticos (BUITONI, 2009. p. 17).

Nesse sentido, examinar as fontes e o modo como elas se ligam ao contexto de produção em que foram publicadas será primordial para entender como esse público era caracterizado, além da referência à beleza e à moda. Para tanto, valemo-nos de anúncios, propagandas, reportagens, entre outros textos contidos nos exemplares a serem analisados.

\section{Jornal da Moças}

O Jornal das Moças foi uma "revista ilustrada quinzenal", produzida no Rio de Janeiro, no século XX, entre os anos de 1914 e 1968, que circulava em todo o Brasil. Seu conteúdo era formado por distintos assuntos, como culinária, moda, comportamento e beleza. Ademais, apresentava anúncios publicitários de diversos produtos. De acordo com Soares e Silva (2013, 
p. 2), os impressos eram distribuídos às quartas-feiras, tanto em bancas quanto pelo serviço de assinatura.

Ainda segundo os autores, a revista era um meio de entretenimento para as mulheres mais jovens e para as senhoras donas de casa, que podiam acompanhar as tendências de moda europeia - mais precisamente a parisiense -, informações sobre beleza, poesia, pintura, utensílios domésticos, receitas culinárias, além de diferentes produtos, por meio da publicidade. Para os pesquisadores, o jornal era um meio de comunicação capaz de ditar as regras de "comportamento social, familiar e religioso", corroborando os costumes da época, ao designar o papel social da mulher.

\section{Exemplar Jornal das Moças, maio de 1914}

No contexto da década de 1910, a beleza era representada, no Jornal das Moças, como algo sutil, pois havia tabus com a maquiagem, relacionada à prostituição. Ao examinar o exemplar, notamos a ausência de anúncios de cosméticos; na realidade, havia dicas caseiras para a confecção de produtos para os cuidados com o corpo e instruções para os cuidados com os cabelos.

\section{Figura 1}

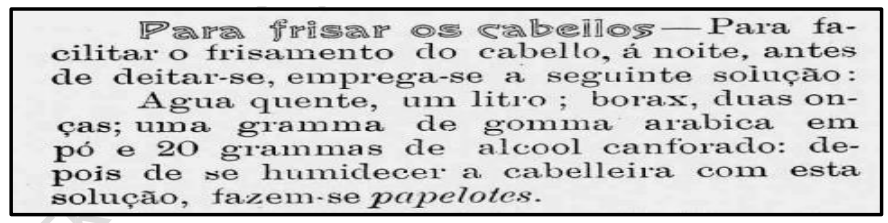

Fonte: JORNAL DAS MOÇAS (1914, p. 21)

Como vemos, na década em questão, já havia a preocupação com o corpo. As mulheres da época entendiam que, para ser elegante, além do uso de roupas da moda, era necessário cuidar da pele. Na seção "A arte de ser elegante", cujo fragmento reproduzimos a seguir, Ivonne, a autora do texto, apresenta algumas impressões acerca do assunto. Para ela, a beleza e elegância estão intimamente ligadas, pois constituem o conjunto da feminilidade.

\section{Figura 2}




\section{F arte de ser elegante \\ 10.ARTE de se ser elegante seria incom- 3. pleta si não fosse além dos cuidados do rosto e do corpo. Lembram-se daquella passagem da «llha dos Pinguins $»$, de Ana- tole? \& A importancia das mulheres não re- monta aos primitivos tempos, replicou Bou- tourlé, ella data do dia em que o santo apos- tolo llies deu bellos vestidos $m$.}

Fonte: JORNAL DAS MOÇAS (1914, p. 16)

Desse modo, não bastava ser bonita; era necessário ser elegante. Em outras palavras, não bastava cuidar do corpo; ser bela e ter leveza eram requisitos importantes para ser considerada uma mulher distinta, esperada pela sociedade. Vale ressaltar que as mulheres viviam sob o modo ditado na Europa. Ademais, a preocupação com o corpo estava muito relacionada à saúde, como podemos observar nas dicas da revista sobre os cuidados necessários a esse público:

Figura 3

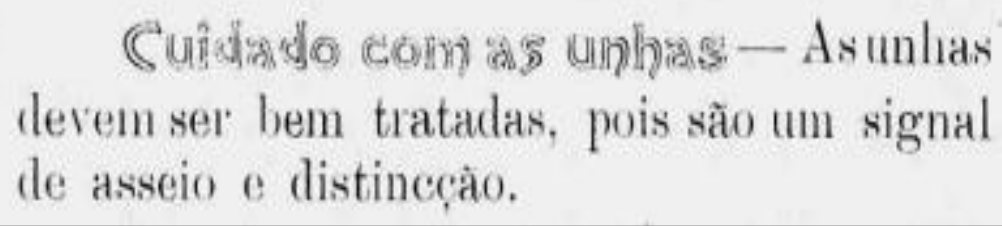

Fonte: JORNAL DAS MOÇAS (1914, p. 20)

Já a moda era considerada fora dos padrões e apresentava características de décadas passadas, devido ao período de escassez da primeira Guerra Mundial. As mulheres usavam roupas com cintura marcada e busto largo. As cores eram claras, com pérolas e flores. $\mathrm{Na}$ cabeça, usavam faixa ou chapéu, tudo delicado e romântico: “[...] uma característica da época: a influência francesa em certos usos e costumes, para não falar do colonialismo cultural da França em relação ao Brasil. Moda significava França” (BUITONI, 2009, p. 63).

\section{Figura 4}




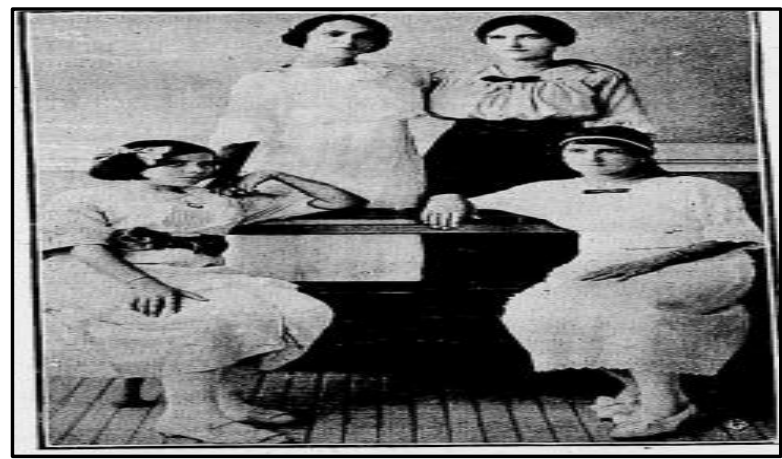

Fonte: JORNAL DAS MOÇAS (1914, p. 7)

Na seção "Modas e Modos", a autora, denominada Giju, protesta contra o calor do Rio de Janeiro dizendo "Estio, com todos os seus horrores, deixou-nos enfim. E a alma das nossas elegantes rejubila, ao sentir os primeiros sopros duma brisa amena, - .despida da callidez pesada dos longos mezes que já lá vão" (1914, p. 19). Apesar de Paris ter outro clima, o país tropical copiava as tendências da cidade-luz, já que ela era a capital da moda e referência para diferentes culturas. No fragmento a seguir, notamos que a revista descreve a última tendência de Paris:

\section{Figura 5}

O vestido tailleur, usado nos ultimos mezes de inverno
cm Paris, que c uma resurreição dos modelos primeiro confec-
cionados no seculo de Luiz XV, esta muito longe de se parecer
com essa ultima creação que já todos viram e que não passa
de um camisão no significado rigoruso do termo. Tailleur nunca

Fonte: JORNAL DAS MOÇAS (1914, p. 20)

Ainda nessa seção, a autora do texto, apesar de tecer algumas críticas à releitura do vestido tailleur, inspirado em modelos de Luís XIV e Luís XV, indica às leitoras o nome e endereço de um ateliê especialista em moda parisiense, com o intuito de manter os costumes da época, mesmo diante do calor escaldante do Brasil.

Outro ponto que merece destaque é a beleza dos pés. De acordo com Ivonne, as mulheres já tinham o costume de usar sapatos com a numeração menor, com intuito de manter os pés pequenos, pois eram considerados o padrão da época. Além do sacrifício, não podiam mostrar desconforto, pois precisavam passar a imagem de graciosidade e feminilidade, ainda que estivessem sob tortura.

Para a autora da seção, o andar da mulher é capaz de revelar sua elegância ou a falta dela. Na concepção de Ivonne (1914), a mulher, ainda que fosse bonita e tivesse os cabelos "de ouro envelhecido ou uns grandes olhos como salgueiro" (p.16), sem a leveza nos pés, não seria sequer admirada. 


\section{Revista Feminina}

Fundada pela intelectual brasileira Virgilina de Souza Salles, a Revista Feminina começou circular em 1914 como folheto quinzenal e, no ano seguinte, tornou-se mensal. Esteve em operação até 1936. Voltada ao público feminino de classe média e alta, tratava de temas como casa, cozinha, moda e beleza.

[...] em 1914, foi lançada, em São Paulo, a Revista Feminina, considerada um exemplo da vinculação entre a imprensa, a indústria e a publicidade.[...] A Revista Feminina pode ser considerada a pioneira no Brasil das publicações voltadas para as mulheres com o formato que se conhece hoje. Fora a estrutura comercial em que se baseava, a revista também apresentou outras inovações em sua diagramação e no número de páginas (SOUZA, 2002, p. 20).

De acordo com Buitoni (2009, p. 58), a publicação era considerada a mais completa, pois continha muitas informações, se comparada às revistas da época. Em síntese, era um produto mais bem dimensionado em relação a seu público-alvo, que estava evoluindo dentro da economia capitalista em consolidação.

\section{Exemplar Revista feminina, fevereiro de 1936}

Na década de 1930, apesar da crise econômica e social, o Brasil também começava o processo de industrialização com a entrada de Getúlio Vargas como presidente da nação. Foi também um período em "que a imprensa feminina se limitava aos assuntos de moda, beleza, crianças etc.” (BUITONI, 2009, p. 85). Nesse contexto, uma das grandes influências foi o cinema de Hollywood.

Figura 6

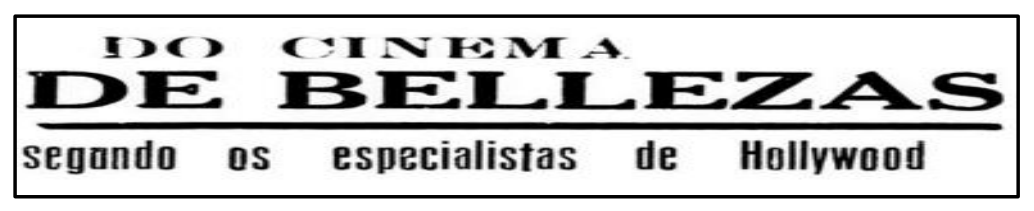

Fonte: REVISTA FEMININA (1936, p. 10)

Dada a influência do cinema, o padrão de beleza da época era inspirado em atrizes hollywoodianas, pois havia a valorização das pernas longas, das curvas, da magreza e dos 
cabelos loiros. Para ficarem mais parecidas com as celebridades, as mulheres buscavam esmaltes e maquiagens, no entanto, estas eram mais delicadas, em comparação às da década de 1920.

Figura 7

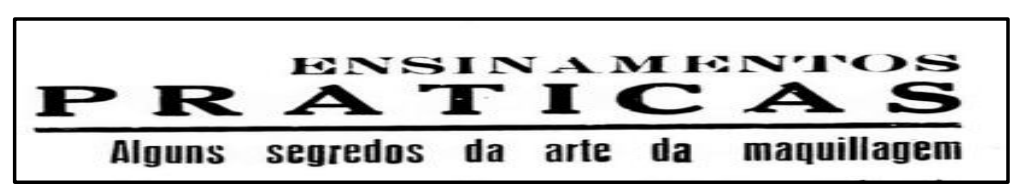

Fonte: FEMININA (1936, p. 9)

A preocupação com o corpo feminino não se limitava aos aspectos mencionados. $\mathrm{Na}$ Revista Feminina, encontramos reportagens e anúncios de cosméticos para a face. Diante disso, constatamos que a mulher já tinha a preocupação em manter o rosto jovial, sem espinhas, sem rugas, para ser sedutora. Entre assuntos tratados do exemplar, estão cuidados com as unhas, uso de água de colônia, preocupação com a higiene íntima e cirurgia de reparação facial.

Figura 8
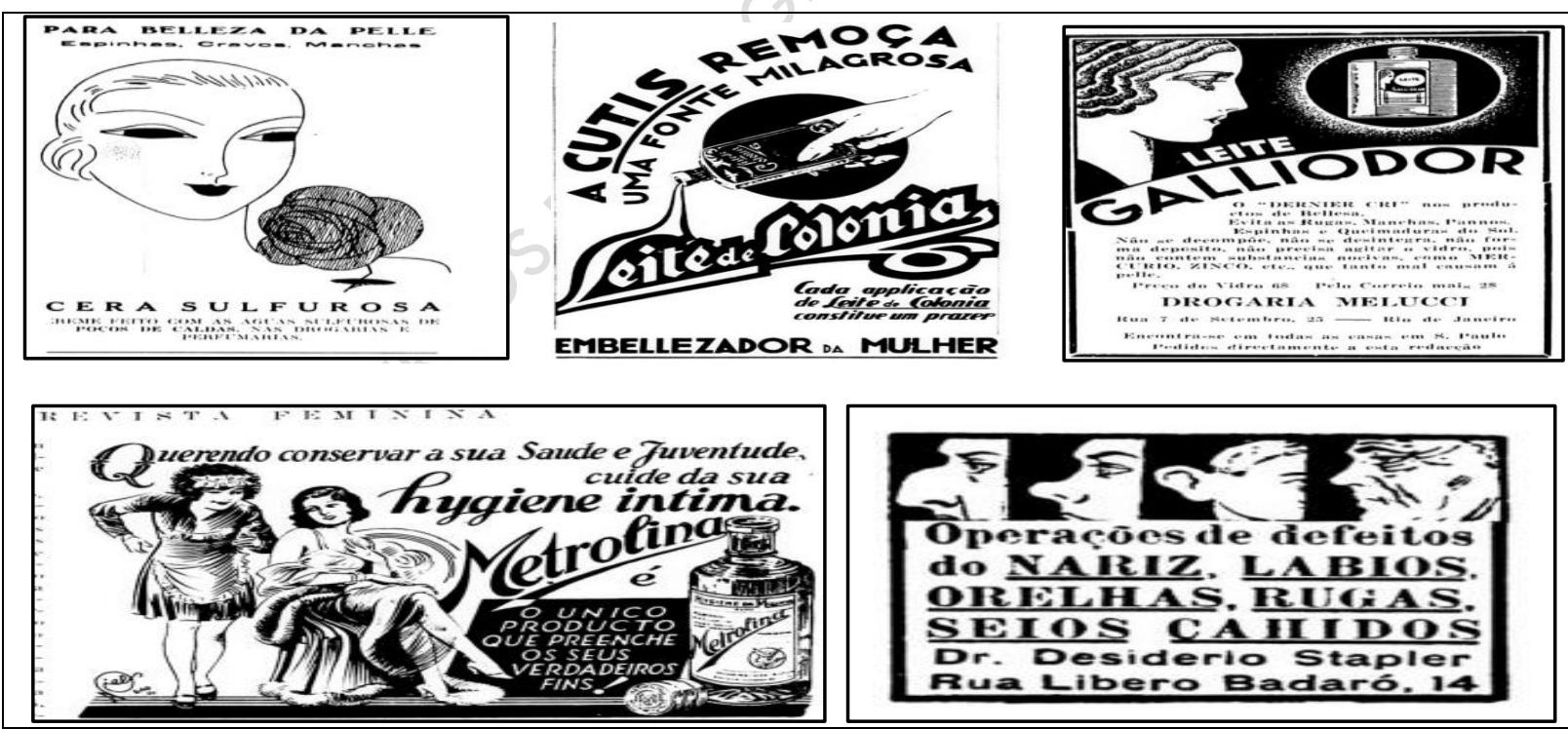

Fonte: REVISTA FEMININA (1936, p. 26- 27-29-30)

Em relação à moda da época, as mulheres adotavam roupas recatadas, mas que valorizassem a cintura. Para as adeptas dos espartilhos, já estavam disponíveis no mercado as cintas elásticas. No mais, observamos que as mulheres mandavam confeccionar as suas roupas, visto que, na revista, havia anúncios de tecidos e moldes de roupas para tricotar. 
Figura 9

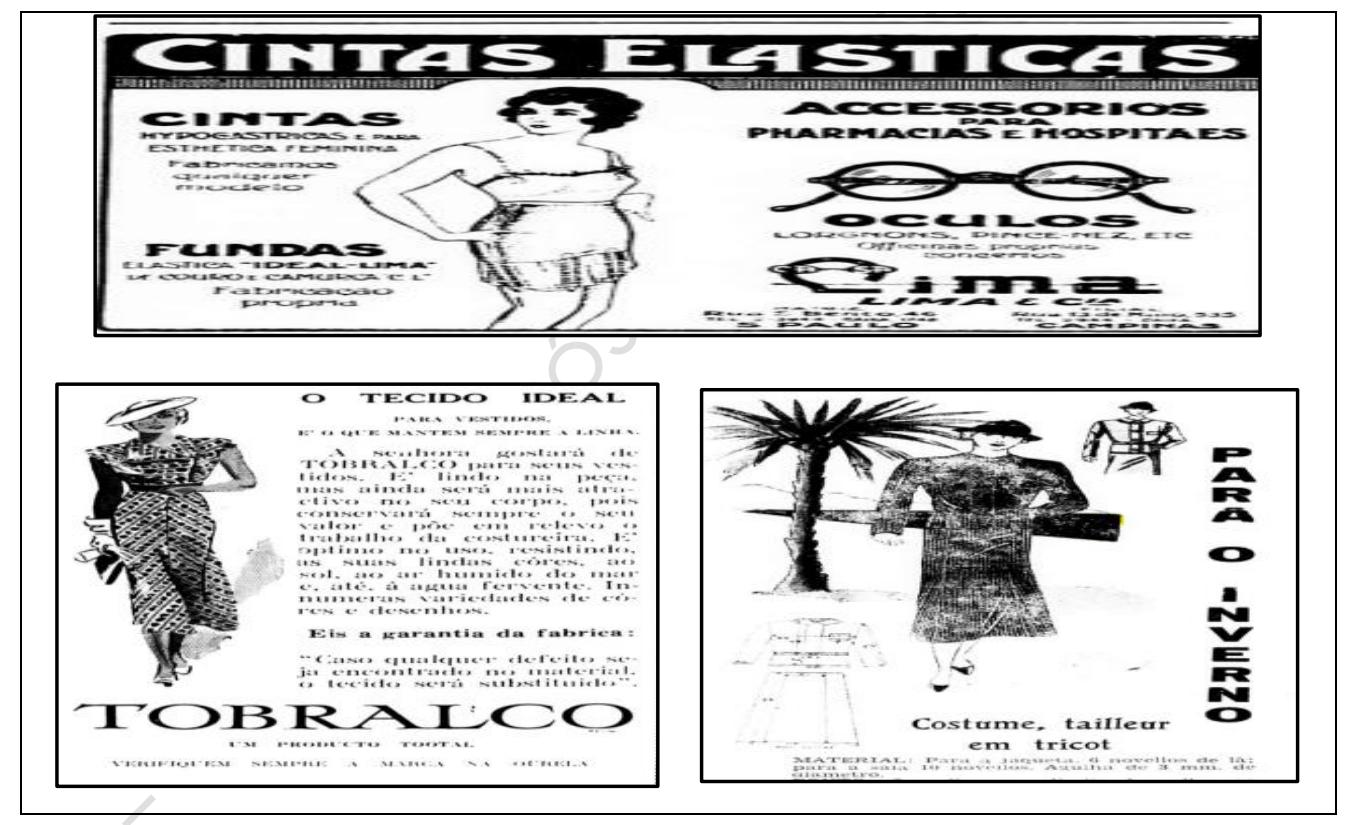

Fonte: REVISTA FEMININA (1936, p. 7- 27 -34)

De acordo com Souza (2002, p. 20), a Revista Feminina era responsável "pela Empresa Feminina Brasileira que fabricava e comercializava produtos voltados para a mulher como cremes de beleza e livros de culinária. [...]. Os lucros obtidos com a venda 'bancavam' a revista e a fabricação de novos produtos".

\section{Revista Querida}


Querida foi uma revista carioca que circulou entre anos 1954 e 1968. Editada pela Rio Gráfica Editora, fazia parte das organizações Globo, pertencentes ao jornalista Roberto Marinho. Conforme Salerno (2009, p. 28), “Querida tinha seu público bem definido; além de trazer escritas as palavras- para adultos- em muitas de suas capas, o próprio título já designava e determinava quem a leria: a revista era claramente dirigida às mulheres". Voltada às damas da classe média, trazia seções sobre casa, cozinha, moda, beleza, cinema, livros, balé, teatro, além de espaço para horóscopo e cartas.

\section{Exemplar Querida, março de 1968}

A década de 1960 ficou conhecida como revolucionária, pois foi palco de acontecimentos relevantes, entre eles: a ampliação dos direitos das mulheres; a invenção da pílula; a segunda onda do feminismo; a revolução sexual; os movimentos Hippie e o Black Power; a intensificação das drogas, e a revolução tecnológica. Também foi a década em que a beleza da mulher era idealizada, padronizada e de difícil alcance. O sexo feminino era bombardeado por anúncios de cosméticos pelas revistas, justificando as tendências estrangeiras.

Figura 10

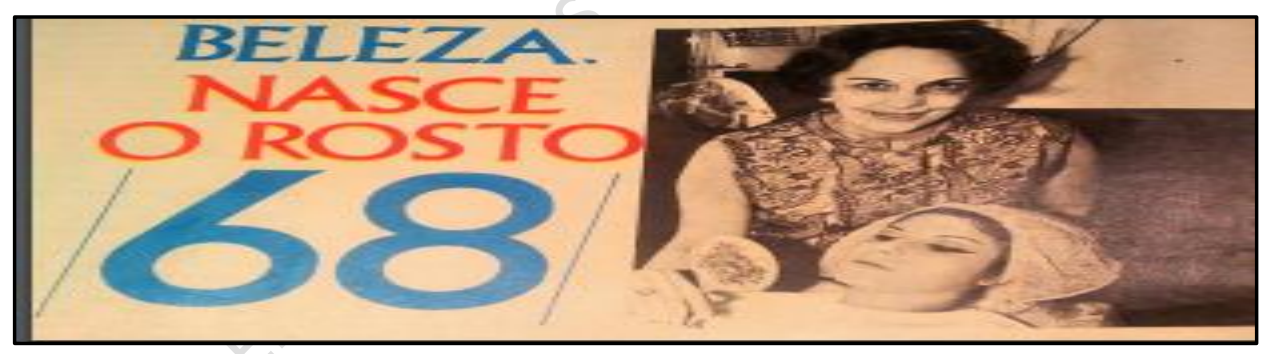

Fonte: QUERIDA (1968, p. 14)

Observamos a forte característica da padronização da beleza na reportagem, "MME CAMPOS cria o rosto de verão 1968", além da influência de outras culturas - "inspirada no traço francês". A reportagem deixa claro para as leitoras a importância de ser bela, usando cosméticos e com luxo: "a beleza exuberante da carioca"; "para as horas elegantes"; "em se tratando de maquilagem requintada" (QUERIDA, 1968, p. 14).

A beleza também é estampada e ressaltada nas vestimentas, e a revista valoriza a juventude, ao aludir às roupas íntimas “[...] Vespa tornam o corpo cada vez mais jovem e ajudam a conservar a juventude de agora [...]" (QUERIDA, 1968, p. 2). Neste exemplar, 
constatamos que a mulher da época deveria ser moderna, elegante, prática, branca, magra e preocupada com a juventude. Por conseguinte, há reportagem de roupas da tendência:

Figura 11

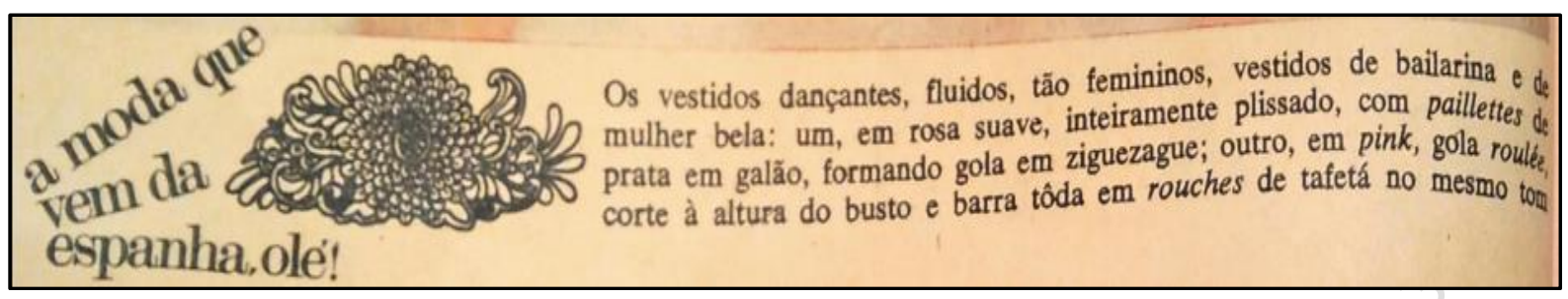

Fonte: QUERIDA (1968, p. 34)

\section{Revista Capricho}

A Capricho foi lançada em 18 de junho de 1952, pelo fundador da Editora Abril, o jornalista Victor Civita. Inicialmente, a revista era de circulação quinzenal e tinha um conteúdo voltado para fotonovelas, chamado à época de "Cinenovela", e histórias de amor desenhadas em quadrinhos. Depois, passou a ser mensal, e trazia - além de contos -, temas como moda, beleza, comportamento e variedades.

Ademais, a Capricho acompanhou a evolução do papel da mulher na sociedade, visto que os seus interesses não mais se limitavam ao lar e à família. Para seguir a mudança no perfil de sua leitora, modificaram-se os seus conteúdos e sua circulação. A sua ascensão ocorreu no século passado, no qual teve grande tiragem e foi considerada a revista mais vendida na América Latina. Também foi a primeira publicação feminina do país destinada ao público adolescente:

[...] com relação à Capricho é possível verificar que ela se propõe a informar a menina sobre tudo o que ela deve saber para se considerar uma adolescente de seu tempo, sendo que a adolescente para quem e de quem fala, é a branca, de classe média e heterossexual. São garotas para quem os rumores sobre o viver a adolescência[...]. A Capricho toma para si um importante papel pedagógico, pois está frequientemente ensinando algo às leitoras, desde os editoriais de moda que mostram que roupas usar até os vários programas de atividades física recomendados por profissionais e artistas, acompanhados de orientações de dietas alimentares e dicas de beleza e comportamento. (GOELLNER; FIGUEIRA, 2002, p. 3). 
No século XXI, a revista passou por novas mudanças e acompanhou a onda da internet, aderindo às plataformas para expor os seus produtos. Em julho de 2015, a Editora Abril deixou de vender os seus exemplares impressos, mantendo apenas o formato digital.

\section{Exemplar Capricho, outubro de 1999}

A década de 1990 é marcada pelo advento da internet e sofreu influências da década anterior, em que os corpos esculturais e a magreza estavam em alta. No exemplar analisado, lemos: "O lance agora é fazer exercícios, seja ele qual for. Para isso existem roupas apropriadas que, além de serem transadas -beleza é fundamental!, são confortáveis, dando total liberdade para você se mexer" (CAPRICHO, 1999, p. 80). Como vemos, para serem consideradas belas, as mulheres deveriam frequentar academias, fazendo uso das tendências até mesmo em locais de atividades físicas.

Figura 12
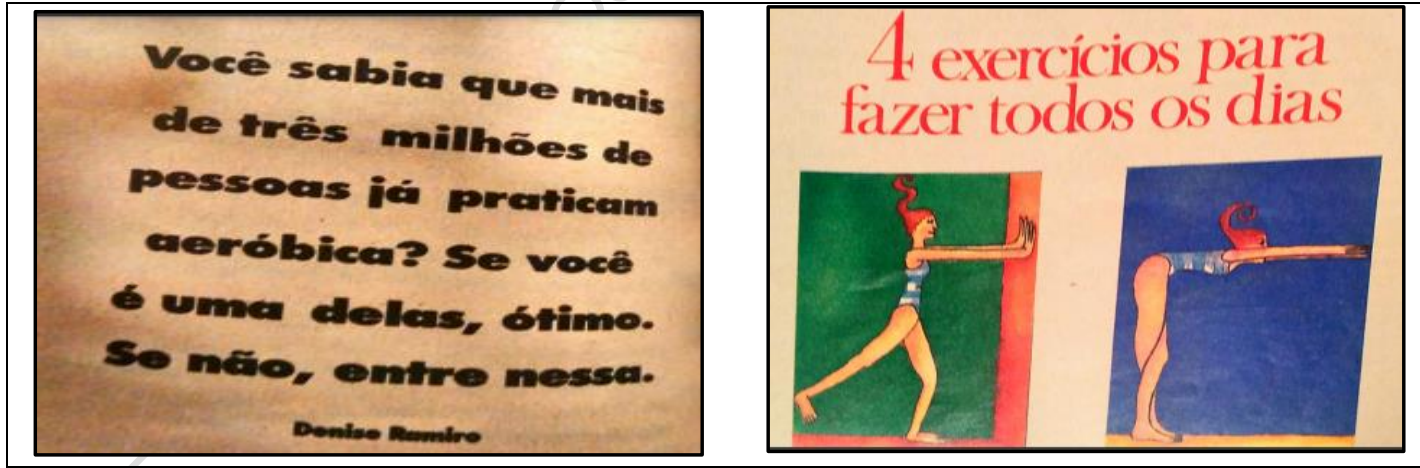

Fonte: CAPRICHO (1999, p. 86-93)

[...] observando a Capricho, é possível identificar que lá estão estampadas diferentes representações de corpo e de feminilidade, suas páginas mostram que, na sociedade contemporânea, o corpo é o local de construção das identidades [...]. Cabe ressaltar: estas representações não são apenas veiculadas pela revista, mas também, são nela produzidas através dos diferentes saberes que circulam nos textos e imagens que falam de diferentes práticas sociais como, por exemplo, as de embelezamento, de condicionamento físico e de saúde. Práticas estas que produzem efeitos e instituem verdades, excluindo e incluindo, em diferentes locais sociais, corpos, sujeitos e grupos (GOELLNER e FIGUEIRA, 2002, p. 3). 
Ainda no exemplar, é nítida a importância do consumismo para estar na moda e ser bela: "esta é uma típica gatinha da Capricho - ela usa jeans, malha de lã colorida, tênis, mochila nas costas e walkman" (CAPRICHO, 1999, p. 11). Isso se verifica também no seguinte trecho: "vem chegando o verão e, com ele, vêm os shorts, camisetas, macaquinhos... Todos com cores fortes, fluorescentes, chocantes, quentérrimas!" (CAPRICHO, 1999, p. 63).

Ademais, se a mulher não tivesse o tamanho considerado dentro dos padrões de beleza, a revista trazia sugestões de roupas para disfarçar as imperfeições, “[...]existem truques: listras e estampas que podem fazer você menos altinha ou menos baixinha e feliz" (CAPRICHO, 1999, p. 70). As publicações também apresentam diversos tipos de cosméticos para realçar a beleza e adequar-se à moda, por exemplo: “a coloração gel é um novo jeito, suave e natural, de dar cor e beleza para os seus cabelos" (CAPRICHO, 1999, p. 68).

De todas as observações do periódico, constatamos que a beleza e a moda deveriam estar sempre presentes na vida da mulher. Para isso, o sexo feminino precisava estar dentro dos padrões estabelecidos, usar roupas da última estação e ter corpo definido.

\section{Revista Vogue Brasil}

A Vogue é a revista feminina em atividade mais antiga de que se tem notícia. Criada em 17 de dezembro de 1892, nos Estados Unidos, por dois aristocratas, o empresário Arthur Baldwin Turnure e o artista e ilustrador Harry Whitney McVickar, a revista americana inicialmente foi um folhetim de moda destinado às mulheres de alta classe da sociedade.

No início do século XX, com sede na cidade de Nova York, passou a pertencer ao grupo Condé Nast Publications, quando se tornou mensal e foi reformulada. Devido à introdução de conteúdos atrativos como moda, beleza, cultura, estilo de vida e passarela, tornou-se a revista que gerava o desejo de consumo para o sexo feminino, além de ter se expandido mundialmente. O Brasil figura entre os países que a Vogue conquistou:

[...]a revista Vogue começa a traçar sua trajetória no mercado editorial brasileiro no ano de 1975, trazida pelas mãos do italiano, residente no Brasil, Luis Carta, um bom conhecedor e executor da dinâmica do meio editorial devido a sua experiência profissional anterior em redações de revistas renomadas como Isto É[...]. No mês de novembro do ano de 2010, a revista Vogue Brasil deixa de ser editada pela Carta Editorial e passa a ficar sob o 
comando a joint venture Edições Globo Condé Nast (MENEGUETE, 2012, p. 12-15).

Classificada como a maior revista de moda da atualidade, ela chegou ao país na ditadura militar. No entanto, o período difícil não atrapalhou o comércio desse produto. Na ocasião, "a mulher brasileira da década de 1970 ansiava não só por obter informações de moda e consumo provenientes de periódicos e revistas internacionais" (MENEGUETE, 2012, p. 14). Ademais, a Vogue acompanhou a mudança de comportamento do sexo feminino e, para atender às suas necessidades, trouxe conteúdos de diferentes informações para dar conta desse novo perfil.

\section{Exemplar Vogue Brasil, janeiro de 2018}

A Vogue do século XXI vive o grande boom da internet, o que possibilitou o contato com o mundo em um click. É o universo de uma geração feminina que tem pressa para tudo, "Detox imediato. Descubra os benefícios do kombucha, a bebida probiótica que virou nova mania [...]?” (VOGUE, 2018, p.15). A preocupação com a beleza e a moda está “a todo vapor”. De acordo com Del Priore (2014, p. 235), em 2010, passamos a ser o segundo país em cirurgias, perdendo apenas para os Estados Unidos: 629 mil. Em 2013, foram 903.124 procedimentos. O caso parece sinalizar a existência de uma "epidemia nacional de vaidade".

Figura 13

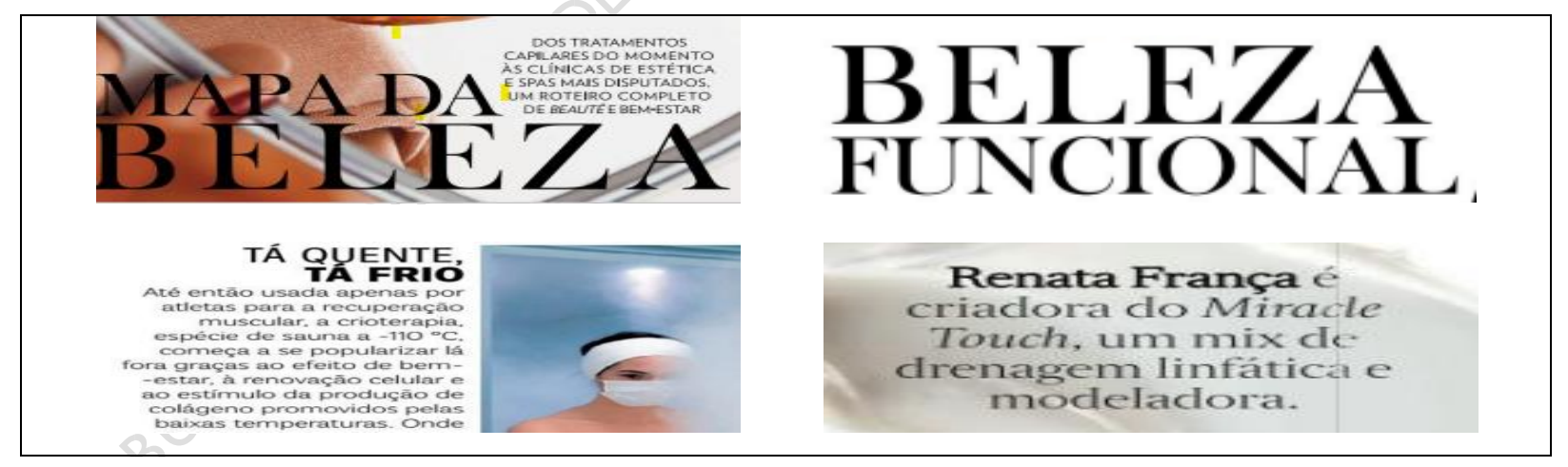

Fonte: VOGUE (2018, p. 15-78-97-100)

Além da procura por academias de musculação, as mulheres buscam clínicas de estética, por falta de tempo de frequentar uma academia ou por querer resultados imediatos. O padrão de beleza do momento está relacionado aos procedimentos estéticos e aos corpos extremamente magros. Assim, o exemplar da Vogue (2018) é bombardeado por informações sobre a última tendência de cosméticos, spas e clínicas de beleza corporal, bem como a moda nas passarelas, 
que impera com enorme fervor: "Decotes inusitados renovam e injetam elegância à moda praia: abuse de peças de gola alta ou com um ombro só, que fazem bela dobradinha com estampas gráficas" (VOGUE, 2018, p. 27).

\section{Conclusão}

Por meio do presente estudo, foi possível compreender, ainda que brevemente, o universo feminino no século XX e no início do século XXI. Ao longo de nossa análise, observamos que o mundo da mulher sempre foi pensado com base no conceito de beleza, também ligada ao corpo e à moda, e em comportamentos esperados por uma sociedade conservadora.

Nesse sentido, verificamos não apenas mudanças ao longo do tempo, mas também a movimentação do coletivo em relação às transformações sociais e culturais. A princípio, notamos uma imprensa dedicada timidamente à mulher e, no decorrer das décadas, as publicações foram traduzindo os ideais da época em que viveram. Por essa razão, foi possível representar o objeto ausente no presente.

Esses materiais não funcionam apenas como suporte de comunicação. Eles representam as ideias de uma sociedade que cultiva a beleza, os ideais de família e corpo. Em um primeiro momento, a imprensa retratou uma mulher brasileira "bela, recatada e do lar". Ao longo da história, o sexo feminino, embora seja adepto dos padrões estabelecidos socialmente e recorra aos diferentes recursos, com intuito de dispor de uma beleza, muitas vezes, inalcançável, deixou para trás algumas regras de convenção social. Considerando a existência de um abismo entre passado e presente, por meio de nossa análise, foi possível recontar os fatos sem interferir no modo como a sociedade de diferentes épocas foi moldada, para, desse modo, entender o presente.

\section{Referências}

ANTONIO, Celso Aparecido de Agostinho. Revistas femininas e a plasticidade do corpo: a progressiva modelagem comunicativa. 2021. Dissertação (Mestrado em Comunicação) Faculdade Cásper Líbero, São Paulo, 2009.

BUITONI, Dulcília Schroeder. Mulher de papel: a representação da mulher na imprensa feminina brasileira. São Paulo: Summus Editorial, 2009. 
CRANE, Diana. A moda e seu papel social: classe, gênero e identidade das roupas. São Paulo: Senac, 2006.

CHARTIER, Roger. A história cultural: entre práticas e representações. Lisboa: DIFEL, 1990.

DEL PRIORE, Mary. Histórias e conversas de mulher. 2.ed. São Paulo: Planeta, 2014.

FÁVERO, Leonor Lopes; MOLINA, Márcia Guedes. As concepções linguísticas no século XIX: a gramática no Brasil. Rio de Janeiro: Lucerna, 2006.

GOELLNER, Silvana Vilodre; FIGUEIRA, Márcia Luiza Machado. Corpo e gênero: a Revista Capricho e a produção de corpos femininos. Revista Motrivivência, Educação Física, Esporte, Lazer e Gênero. n. 19, 2002.

JORNAL DAS MOÇAS. Ano I, n. I, 1914. Disponível em: http://memoria.bn.br/pdf/111031/per111031_1914_00001.pdf. Acesso em: 01 ago. 2021.

KRENISKI, Gislania Carla; AGUIAR, Maria do Carmo Pinto. O jornal como fonte histórica: a representação e o imaginário sobre o "Vagabundo" na imprensa feminina brasileira (19891991). Anais do XXVI Simpósio Nacional de História - ANPUH. São Paulo, julho 2011. Disponível em:

http://www.snh2011.anpuh.org/resources/anais/14/1300663138_ARQUIVO_artigovagabundo s-1.pdf. Acesso em: 1 ago. 2021.

LIMA, Sandra Lúcia Lopes. A imprensa feminina, Revista Feminina: a imprensa feminina no Brasil. Disponível em: https://periodicos.ufsc.br/index.php/motrivivencia/article/view/950 acesso em: 25 set. 2021.

MARTINO, Agnaldo. Apresentação. In: MARTINO, Agnaldo (ORG.). Itinerários Investigativos: história das ideias linguísticas: apropriação e representação. São Paulo: Blucher, 2021. (p. 3-4).

MENEGUETE, Andréia. Vogue Brasil e sua relação afetiva e emocional com a leitora. Monografia - Universidade de São Paulo - USP. São Paulo, 2012. (páginas- 46)

POLLINI, Denise. Breve história da moda. In: Coleção Saber de tudo. São Paulo, 2007.

REVISTA CAPRICHO, n. 662. São Paulo: Editora Abril. São Paulo, 1999.

REVISTA FEMININA, ano XXIII, n. 261 Disponível em: https://bibdig.biblioteca.unesp.br/handle/10/6326. Acesso em 10 ago. 2021.

REVISTA QUERIDA, n. 337 . Rio de Janeiro: Rio Gráfica e Editora, 1968.

REVISTA VOGUE BRASIL. São Paulo: Edições/Globo, 2018.

SALERNO, Laura Peretto. Querida ensina: preceitos de comportamento femininos em páginas da revista Querida (1958-1968). 2009. Dissertação (Mestrado em Educação) - Programa de Pós-Graduação em Educação - Universidade do Estado de Santa Catarina, Florianópolis, 2009. 
SILVA, Alexandre José da . História das Ideias Linguísticas: história, ideias e possibilidades investigativas. In: MARTINO, Agnaldo (ORG.). Itinerários Investigativos: história das ideias linguísticas: apropriação e representação. São Paulo: Blucher, 2021. (p. 11-39).

SOARES, Diego dos Santos; SILVA, Ursula Rosa da. O Jornal das Moças: Uma narrativa ilustrada das mulheres de 30 a 50 e sua passagem por pelotas nas décadas. Disponível em: https://periodicos.ufpel.edu.br/ojs2/index.php/Arte/article/view/3013/2594. Acesso em: 24 set. 2021.

SOUZA, Lidiane Aparecida Silva de. Imprensa feminina: a mulher vista nas páginas das revistas. 2002. Monografia do curso de Comunicação Social - Universidade Federal de Juiz de Fora, Juiz de Fora, 2002.

WOLF, Naomi. $O$ mito da beleza: como as imagens de beleza são usadas contra as mulheres. 16.ed. Trad. Waldéa Barcellos. Rio de Janeiro: Editora Rosa dos tempos, 2021.

\title{
WOMEN'S BEAUTY AND FASHION REPRESENTED IN THE WOMEN'S PRESS OF THE 20TH AND EARLY 21ST CENTURY
}

\begin{abstract}
In this article, we investigate magazines produced in the 20th and early 21 st centuries, the way in which women are represented. Our study focuses on five publications: Jornal das Moças (1914); Revista Feminina (1936); Querida (1968); Capricho (1999); Vogue Brasil (2018). For the present analysis, we have the intertwining between two scientific areas, History and Linguistics, which resulted in the History of Linguistic Ideas. This study, although fragmented, as we made a brief selection of different materials over two centuries, enables verification and historiographical knowledge with the help of these sources and demonstrates a new look at History, distinct from that which valued only heroic figures, the great deeds by them and the achievements judged as important. In this way, we verify the postulate by Chartier (1990, p.16-17), precursor of the idea that defends the way "how, in different places and moments, a certain social reality is constructed and given to be read".
\end{abstract}

Keywords: Women's press. Representation. Beauty. Fashion.

Envio: 29/11/2021. 